\title{
Detection of Glaucomatous Progression
}

\author{
Linda M Zangwill
}

Hamilton Glaucoma Center, Department of Ophthalmology, University of California San Diego, La Jolla, CA

\section{INTRODUCTION}

Glaucoma is a progressive optic neuropathy identified by characteristic optic disc, retinal nerve fiber layer (RNFL) and visual field damage and change that occur as a result of retinal ganglion cell damage and death. Detecting structural and functional change is one of the most challenging aspects of glaucoma management. ${ }^{1-4}$ Detecting progression requires detailed documentation of the appearance of the optic disc and visual field at each visit so that change over time can be identified. In the clinical setting, structural change is usually identified based on a thorough clinical examination, with a drawing or written description of the optic disc and retinal nerve fiber layer often augmented with subjective assessment of optic disc photographs to summarize the examination results. Automated perimetry provides objective documentation of visual function that can be used to compare visual fields over time.

Fortunately, objective tools to document structural and functional change have been improving. In addition to subjective assessment of the optic disc and RNFL by clinical examination or photograph review objective methods including confocal scanning laser ophthalmoscopy, scanning laser polarimetry and optical coherence tomography are available to provide documentation of the optic disc and RNFL with sophisticated statistical analyses for glaucoma management. In addition to standard automated perimetry, selective perimetric techniques such as short wavelength automated perimetry (SWAP) and frequency doubling perimetry are now available to detect and monitor glaucomatous visual field changes.

Naturally, the ability to detect structural and functional change in glaucoma will vary depending on which structural and functional techniques are used. Other factors, including how glaucomatous change is defined, and the severity of disease will also affect the ability to detect glaucomatous change. This brief overview will summarize what we know about the temporal relationship between structural and functional change in glaucoma and how this information can be used in clinical practice. This review will focus on the limited number of well- designed longitudinal studies (randomized clinical trials and observational cohort studies) that measured structural and functional change over time in order to answer the question: Is structural change usually detectable before functional change in glaucoma? This review will also briefly highlight study design issues that may explain differences in results across studies so that clinicians can better apply the information to their specific clinical populations.

\section{RANDOMIZED CLINICAL TRIALS}

In the past, most randomized clinical trials of glaucoma therapy relied on the reduction of IOP as the primary study endpoint. The studies that did not rely solely on IOP reduction, most often examined the progression of visual field loss (e.g. the Advanced Glaucoma Intervention Study, ${ }^{5}$ and Collaborative Initial Glaucoma Treatment Study ${ }^{6}$ ) and did not include an independent measure of optic disc structure as a primary study endpoint. More recently three randomized clinical trails (Ocular Hypertension Treatment Study (OHTS), ${ }^{7}$ Early Manifest Glaucoma Study (EMGT), ${ }^{8}$ and the European Glaucoma Prevention Study (EGPS) ${ }^{9}$ have included assessment of the optic disc along with visual field testing as primary endpoints for open angle glaucoma. These well-designed studies provide important information on the temporal relationship between structural and functional change in early glaucoma (Tables 1 and 2).

The OHTS and EGPS evaluated whether ocular hypotensive treatment delayed or prevented the development of glaucoma in participants with ocular hypertension. The OHTS, a National Eye Institute multi-center randomized clinical trial of 1636 ocular hypertensive patients, found that topical ocular hypotensive medication was effective in delaying and/or preventing the onset of POAG. ${ }^{10}$ In contrast to the OHTS, the EGPS a multi-center randomized, double-masked, placebo controlled study of 1,077 ocular hypertensives found that neither the degree of IOPlowering nor the rate of progression to POAG was statistically different between the dorzolamide treated and placebo groups. ${ }^{11}$ 
Table 1: Study design features of the OHTS, EGPS and EMGT

\begin{tabular}{|c|c|c|c|}
\hline & OHTS $^{10}$ & EGPS $^{11}$ & $\mathrm{EMGT}^{16}$ \\
\hline Stage of disease at study entry & $\begin{array}{l}\text { Ocular hypertensives: } \\
\text { No sign of structural or } \\
\text { functional damage }\end{array}$ & $\begin{array}{l}\text { Ocular hypertensives: } \\
\text { No sign of structural or } \\
\text { functional damage }\end{array}$ & $\begin{array}{l}\text { Early glaucoma: } \\
\text { Reproducible field damage at baseline } \\
\text { (99\% had optic disc pathology at } \\
\text { baseline) }\end{array}$ \\
\hline $\begin{array}{l}\text { Normal tension/ } \\
\text { exfoliation included }\end{array}$ & No/No & $\begin{array}{l}\text { No/Yes } 1.6 \% \text { of study } \\
\text { population }\end{array}$ & Yes/Yes $10 \%$ of study population \\
\hline $\begin{array}{l}\text { Structural change } \\
\text { definition }\end{array}$ & $\begin{array}{l}\text { Stereophotography } \\
\text { "clinically significant } \\
\text { optic disc deterioration } \\
\text { attributed to POAG" }\end{array}$ & $\begin{array}{l}\text { Stereophotography } \\
\text { visually recognizable } \\
\text { narrowing of the } \\
\text { neuroretinal rim not } \\
\text { attributable to photographic } \\
\text { artifacts }\end{array}$ & $\begin{array}{l}\text { Flicker chronoscopy and side-by-side } \\
\text { comparisons of fundus photographs }\end{array}$ \\
\hline Structural change graders & $\begin{array}{l}\text { Masked graders from } \\
\text { Optic disk reading } \\
\text { center }\end{array}$ & Masked graders & Masked graders \\
\hline $\begin{array}{l}\text { Required repeatability of } \\
\text { structural change }\end{array}$ & Yes & No & $\begin{array}{l}\text { Suspected or definite changes confirmed } \\
\text { using a second set of photographs }\end{array}$ \\
\hline Frequency of photography & Annually & Annually & At 3 and 6 months, then every 6 months \\
\hline $\begin{array}{l}\text { Functional change } \\
\text { definition }\end{array}$ & $\begin{array}{l}\text { Humphrey field } \\
\text { Analyzer: } \\
\text { GHT or CPSD outside } \\
\text { normal limits }\end{array}$ & $\begin{array}{l}\text { Humphrey field } \\
\text { Analyzer or Octopus: } \\
\text { 1. } 3 \text { or more adjacent } \\
\text { points that change } \\
>5 \mathrm{~dB} \text { from baseline, OR } \\
\text { 2. } 2 \text { or more adjacent } \\
\text { points that change } \\
>10 \mathrm{~dB} \text { from baseline, OR } \\
\text { 3. A difference of } 10 \mathrm{~dB} \\
\text { or more across the nasal } \\
\text { horizontal meridian in at } \\
\text { least } 2 \text { adjacent points }\end{array}$ & $\begin{array}{l}\text { Humphrey field } \\
\text { Analyzer: the pattern } \\
\text { deviation based } \\
\text { glaucoma change } \\
\text { probability maps with the } \\
\text { same } 3 \text { changing test points } \\
\text { (not necessarily contiguous) }\end{array}$ \\
\hline $\begin{array}{l}\text { Required repeatability of } \\
\text { functional change }\end{array}$ & $\begin{array}{l}\text { Confirmed on } 3 \\
\text { consecutive exams } \\
\text { with the same index } \\
\text { and location }\end{array}$ & $\begin{array}{l}\text { Repeatable in the same } \\
\text { locations in } 3 \text { consecutive } \\
\text { exams }\end{array}$ & $\begin{array}{l}3 \text { exact test point } \\
\text { locations confirmed on } 3 \\
\text { consecutive exams }\end{array}$ \\
\hline Frequency of VF Testing & Every 6 months & Every 6 months & Every 3 months \\
\hline
\end{tabular}

Although these studies came to different conclusions regarding the effect ocular hypertensive treatment on the development of glaucoma, both studies reported a substantial proportion of eyes with either structural or functional change as the first sign of glaucoma. Specifically, the OHTS ${ }^{10}$ and EGPS ${ }^{11}$ showed that, in many eyes, repeatable structural defects were the first sign of glaucoma (55\% and $40 \%$ respectively), whereas, in some eyes, functional defects were the first sign of progressive change (35\% and $60 \%$, respectively). A very small proportion of eyes (10\% in the OHTS and $0 \%$ in the EGPS) showed structural and functional change at the same time. It should be noted that the definition of the study endpoints of the OHTS and EGPS were similar (but not identical), ${ }^{12}$ with both using masked independent assessment of stereophotography and repeatable visual field change confirmed by an endpoint committee (Table 1). In addition, both studies reported good reproducibility in the assessment of the stereophotographs. ${ }^{13-15}$

The EMGT reported that in early glaucoma patients, treatment was effective in reducing glaucomatous progression. ${ }^{16}$ EMGT compared the development of optic disk 
Table 2: First detectable structural and functional change in the OHTS, EGPS and EMGT

\begin{tabular}{llll}
\hline & OHTS ${ }^{10}$ & $E G P S^{11}$ & EMGT \\
\hline Total number of endpoints & 125 & 106 & 136 \\
Structural change first & $69(55 \%)$ & $42(40 \%)$ & $1(1 \%)$ \\
Functional change first & $44(35 \%)$ & $64(60 \%)$ & $117(86 \%)$ \\
Structural and functional change at the same time & $12(10 \%)$ & 60 months & 72 months (median) \\
Length of follow-up & 78 months (median) & $13.4 \% / 14.1 \%$ & $45 \% / 62 \%$ \\
$\begin{array}{l}\text { Cumulative probability of developing an endpoint } \\
\text { (treated/observation) }\end{array}$ & $4.4 \% / 9.5 \%$ & & \\
\hline
\end{tabular}

and visual field changes in 129 early glaucoma patients randomized to the treatment arm (treatment with betaxolol and argon laser trabeculoplasty) to 126 patients assigned to the observation arm. In contrast to OHTS and EGPS, EMGT used utilized flicker chronoscopy and side-by-side comparisons of non-stereoscopic fundus photographs for identifying optic disc change and the glaucoma change probability maps (based on visual field pattern deviation changes) for detecting functional change. Of the 136 eyes that progressed, the vast majority (86\%) was detected by visual function only while only $1 \%$ had optic disc change. Another 13\% of the progressing eyes were identified by both structural and functional change at the same time. The higher proportion of eyes with visual field as opposed to optic change in EMGT compared to OHTS and EGPS can be explained in part by the lack of stereophotography assessment of optic disc change as well as to differences in the study populations and stage of disease. For example, EMGT was a population-based study of Scandinavians with early glaucoma, with 23 (10\%) participants with documented exfoliation at baseline. The EGPS cohort was drawn from several European countries and reported only 18 patients (1.7\%) with pseudoexfoliation at baseline, while the OHTS cohort excluded eyes with pseudoexfoliation, ${ }^{12}$ and by design included approximately 25\% African Americans.

\section{OBSERVATIONAL COHORT STUDIES}

Early observational cohort studies highlighted the importance of structural evaluation in glaucoma management by providing evidence that RNFL and optic disc change based on photographic assessment can occur before detectable visual field change. ${ }^{17-19}$ Other early studies suggested that progression was detectable earlier using short wavelength automated perimetry (SWAP) than SAP. ${ }^{20-22}$ These early studies were small, often with some bias in patient selection that make it difficult to generalize the results to the general population of glaucoma patients and suspects. For example, Sommer et al, ${ }^{17}$ reported that in 1344 eyes with elevated IOP over a 6-year period, up to $60 \%$ of eyes (depending on the grader) had RNFL defects (qualitative assessment with red-free photography) 6 years before the onset of Goldmann based visual field loss. The often cited $60 \%$ of eyes with RNFL defects preceding visual field damage was based on a very small sample of 6 out of 10 eyes. With respect to selective visual field loss, the early studies often required SAP but not SWAP testing to be normal at study entry, resulting in a biased comparison of the diagnostic accuracy of the two types of visual field tests; ${ }^{20-22}$ SWAP damage could be detected at study entry before SAP, while a SAP defect at study entry resulted in exclusion from the study. Despite these methodological limitations, the overall conclusion is consistent from these studies; both structural and functional change can be the first sign of glaucomatous progression.

More recently, well-designed studies using imaging and selective functional tests have been initiated to evaluate whether new tests are better at identifying glaucomatous progression. These studies also provide information on the temporal relationship between structural and functional change. Because glaucoma is a slowly progressing disease, especially when treated, studies investigating change over time require extensive follow-up. Therefore, to date there are only a limited number of published studies that include both imaging instruments and standard or selective visual function tests to assess glaucomatous progression. ${ }^{23-32}$ Since the HRT is the only optical imaging technology whose image acquisition technique has remained stable since its initial commercialization, most of the longitudinal imaging studies compare change in HRT optic disc topography to SAP. ${ }^{24-28,30,33-36}$ Studies assessing new visual function tests and analysis methods for progression detection often compare results to stereophotography or HRT topographic change. ${ }^{23,28,31,37}$ Chauhan et $\mathrm{al}^{30}$ reported that 31 (40\%) of 77 glaucoma eyes showed progression only based on HRT Topographic Change Analysis (TCA), 22 (29\%) eyes showed changes on both HRT TCA and SAP (defined using Statpac Glaucoma Change Probability 
Detection of Glaucomatous Progression

Table 3: Detectable structural and functional change in selected observational cohort studies

\begin{tabular}{|c|c|c|c|c|c|c|}
\hline & & Chauhan $^{30}$ & Kamal $^{27}$ & Artes $^{31}$ & Strouthidis $^{25}$ & Girkin $^{37}$ \\
\hline & Diagnosis & OAG & OHT & OAG & ОНТ & OAG \\
\hline & N (eyes) & 77 & 164 & 84 & 198 & 47 \\
\hline Patients & $\begin{array}{l}\text { Length of } \\
\text { follow-up }\end{array}$ & $\begin{array}{l}5.5 \text { years } \\
\text { median }\end{array}$ & $\begin{array}{l}16-21 \\
\text { months }\end{array}$ & $\begin{array}{l}7.4 \text { years median } \\
\text { (range } 2 \text { to } 9 \text { ) }\end{array}$ & 2 to 7 years & 2 to 9 years \\
\hline \multirow[b]{2}{*}{$\begin{array}{l}\text { Structural } \\
\text { assessment }\end{array}$} & Test Used & HRT & HRT & HRT & HRT & Stereophotography \\
\hline & $\begin{array}{l}\text { Progression } \\
\text { criteria }\end{array}$ & TCA & $\begin{array}{l}\text { Cup and rim } \\
\text { change } \\
\text { greater than } \\
\text { variability }\end{array}$ & $\begin{array}{l}\text { TCA } \\
\text { ( } 3 \text { criteria levels) }\end{array}$ & $\begin{array}{l}\text { Rim area } \\
\text { regression } \\
\text { (3 criteria levels) }\end{array}$ & $\begin{array}{l}\text { Qualitative } \\
\text { assessment }\end{array}$ \\
\hline \multirow[b]{2}{*}{$\begin{array}{l}\text { Functional } \\
\text { assessment }\end{array}$} & Test Used & SAP & SAP & $\begin{array}{l}\text { SAP } \\
\text { HRP }\end{array}$ & SAP & $\begin{array}{l}\text { SAP } \\
\text { SWAP }\end{array}$ \\
\hline & $\begin{array}{l}\text { Progression } \\
\text { Criteria }\end{array}$ & $\begin{array}{l}\text { Glaucoma } \\
\text { change } \\
\text { probability }\end{array}$ & $\begin{array}{l}\text { AGIS score } \\
\text { change from } \\
0 \text { to }>1\end{array}$ & $\begin{array}{l}\text { Pattern deviation } \\
\text { ( } 3 \text { criteria levels) }\end{array}$ & $\begin{array}{l}\text { Pointwise linear } \\
\text { regression } \\
\text { (3 criteria levels) }\end{array}$ & $\begin{array}{l}\text { AGIS score } \\
\text { clinical scoring } \\
\text { system }\end{array}$ \\
\hline \multirow[t]{2}{*}{$\begin{array}{l}\text { Event or } \\
\text { rate based }\end{array}$} & & Event & Event & Event and rate & Rate & Event \\
\hline & Structural only & $40 \%$ & $29 \%$ & $17 \%$ to $42 \% *$ & $9 \%$ to $21 \% *$ & $13 \%$ to $32 \% * \wedge$ \\
\hline \multirow{3}{*}{$\begin{array}{l}\text { Type of } \\
\text { change }\end{array}$} & Functional only & $4 \%$ & $5 \%$ & $17 \%$ to $42 \% *$ & $15 \%$ to $20 \% *$ & $0 \%$ to $6 \% * \wedge$ \\
\hline & $\begin{array}{l}\text { Structural and } \\
\text { functional }\end{array}$ & $29 \%$ & $8 \%$ & $4 \%$ to $19 \% *$ & $3 \%$ to $12 \% *$ & $15 \%$ to $34 \% * \wedge$ \\
\hline & No progression & $27 \%$ & $59 \%$ & $58 \%$ to $83 \% *$ & $46 \%$ to $73 \% *$ & $47 \%$ to $53 \% * \wedge$ \\
\hline
\end{tabular}

*Criteria dependent, ^Calculated from reported results, OAG—open angle glaucoma, OHT—ocular hypertension, HRT—Heidelberg retina tomograph, TCA-Topographic change analysis, SAP-Standard automated perimetry, HRP-High pass resolution perimetry, SWAP-Short wavelength automated perimetry, AGIS-Advanced glaucoma intervention study

Analysis), and only 3 (4\%) showed change only on SAP. Table 3 summarizes the results of selected observational cohort studies. In general, regardless of the type of structural or functional test used, these studies suggest that the first sign of glaucomatous change can be either structural or functional. Differences between these studies can be explained at least in part by differences in the criteria used to define glaucomatous progression. For example, several studies have shown that various algorithms used in clinical trials for identifying glaucomatous visual field progression identify different proportions of patients with progressive visual field loss. ${ }^{23,38,39}$

A number of well-designed studies explicitly assess the effect of applying different stringency criteria for defining structural and functional progression in the same study population. Artes and Chauhan ${ }^{31}$ compared SAP, high pass resolution perimetry and HRT topographic change analysis in glaucoma patients utilizing three criteria of change (least conservative, intermediate and conservative) for each test. Regardless of the criteria, they found rather limited agreement between SAP, high pass resolution perimetry and HRT for detecting change after an average of 7 years of follow-up and concluded that these indicators of structural and functional change provide "largely independent measures of progression". Specifically, among the 60 patients classified as progressing using the least conservative criteria by at least one test, only $6(10 \%)$ met the criteria for all 3 tests. Similarly, using the most conservative criteria, only 2 of the 27 (7\%) progressing eyes showed progression on all 3 tests. Strouthidis et al. ${ }^{25}$ compared rates of rim area and SAP sensitivity change over time in 198 ocular hypertensive patients and found that, depending on the stringency of the criteria, between $8 \%$ and $21 \%$ of eyes had documented rim area change, and another 15 to $20 \%$ had documented change in visual field sensitivity. Only 3 to $12 \%$ had both documented rim area and visual field sensitivity change. The authors conclude that "The results indicate that, in patients with ocular hypertension, monitoring of both VF and optic disc is necessary, as agreement between optic disc and VF progression is the exception rather than the rule.” 
In summary, using a variety of diagnostic tests and definitions of progression from observational cohort studies provide evidence that in some eyes (13 to $42 \%$ ), glaucomatous structural change is detected first, while in other eyes (4 to $42 \%)$ functional change is the first sign of glaucoma. ${ }^{23-}$ 28,30,31,35,37 Moreover, these studies consistently show that in fewer eyes (3 to 34\%), structural and functional changes are detected at the same time.

\section{DISCUSSION}

There are many possible explanations for why in some eyes, structural change is detected first, whereas in others, functional change is detected first (See Hood and Kardon ${ }^{29}$ for an excellent discussion of this issue). First, the ability to detect structural and functional damage depends on the instrument and parameters used to detect it. Since we cannot measure retinal ganglion cell function directly, we must rely on surrogates such as structural and functional testing. For example, visual function tests are designed to indirectly assess ganglion cell dysfunction. In some eyes, these psychophysical changes can be identified before cell death or before an anatomical structural change can be detected. It is also likely that in some eyes, structural changes can be detectable before visual sensitivity loss in areas of the visual field where redundancy of ganglion cells is high. Currently, there is no consensus on the best test or criteria for detecting glaucomatous change. ${ }^{2}$ Moreover, the definition of progression in clinical studies and clinical practice is determined by balancing the magnitude of detectable change (signal) desired, with the variability of its detection (noise). If one tries to detect the earliest sign of change, it may be difficult to identify reproducibly and may lead to false positives; a larger change may be more reproducibly detected. Balancing these considerations to detect progression in an individual patient may be different from identifying small differences in the average course of disease in a group of patients in a clinical study. ${ }^{2}$ Finally, as the reproducibility of tests varies by individual, type of test, and stage of disease, the test with the lowest variability (structural or functional) may reveal the first sign of glaucomatous change for a particular individual patient. ${ }^{29,31}$

\section{Which Technique to Use?}

Techniques to monitor structural and functional change are improving. Based on the evidence from a limited number of studies available, there is no one structural or functional test or analysis technique that clearly outperforms the others in the detection of progression. ${ }^{2,40,41}$ (See Anderson et $\mathrm{al}^{2}$ for a discussion of test criteria important for the detection of progression). A recent American Academy of Ophthalmology Opthalmic Technology Assessment Report reviewed imaging instruments for detection of glaucoma and its progression and concluded that "Based on studies that have compared the various available technologies directly, there is no single imaging device that outperforms the others in distinguishing patients with glaucoma from controls. ${ }^{40}$ Sakata et $\mathrm{al}^{41}$ recently reviewed the evidence for selective perimetry in glaucoma management and concluded that “....visual dysfunction in eyes with early glaucoma varies significantly between individuals and no single technique is superior to the others in all patients."

Techniques with lower measurement variability will be more likely to detect repeatable change. Each technique has advantages and disadvantages, and it is important for the clinician to understand the strengths and limitations of the technique used in their clinic. ${ }^{41-44}$ Moreover, both structural and functional techniques should be used in conjunction with a careful clinical examination.

\section{SUMMARY}

Consistent evidence from clinical trials and observational cohort studies suggests that the first sign of glaucomatous change can be structural or functional. This is true in studies of ocular hypertensive patients and patients with early to moderate glaucoma using a variety of techniques and definitions of glaucomatous change. Based on current evidence, there is no one structural or functional technique that outperforms the others in detecting glaucomatous progression. Therefore, monitoring both structural and functional change in conjunction with a thorough clinical examination is essential for proper management of glaucoma patients.

\section{REFERENCES}

1. Johnson CA, Cioffi GA, Liebmann JR, Sample PA, Zangwill LM, Weinreb RN. The relationship between structural and functional alterations in glaucoma: a review. Semin Ophthalmol 2000;15:221-33.

2. Anderson DR, Chauhan B, Johnson C, Katz J, Patella VM, Drance SM. Criteria for progression of glaucoma in clinical management and in outcome studies. Am J Ophthalmol 2000;130:827-9.

3. Girkin CA. Relationship between structure of optic nerve/nerve fiber layer and functional measurements in glaucoma. Curr Opin Ophthalmol 2004;15:96-101.

4. Giangiacomo A, Garway-Heath D, Caprioli J. Diagnosing glaucoma progression: current practice and promising technologies. Curr Opin Ophthalmol 2006;17:153-62.

5. The Advanced Glaucoma Intervention Study (AGIS): 1. Study design and methods and baseline characteristics of study patients. Control Clin Trials 1994;15:299-325.

6. Musch DC, Lichter PR, Guire KE, Standardi CL. The Collaborative Initial Glaucoma Treatment Study: study design, methods, and baseline characteristics of enrolled patients. Ophthalmology 1999;106:653-62.

7. Gordon MO, Kass MA. The Ocular Hypertension Treatment Study: design and baseline description of the participants. Arch Ophthalmol 1999;117:573-83. 
8. Leske MC, Heijl A, Hyman L, Bengtsson B. Early Manifest Glaucoma Trial: design and baseline data. Ophthalmology 1999;106:2144-53.

9. Miglior S, Zeyen T, Pfeiffer N, Cunha-Vaz J, Torri V, Adamsons I. The European glaucoma prevention study design and baseline description of the participants. Ophthalmology 2002;109:161221.

10. Kass MA, Heuer DK, Higginbotham EJ, et al. The Ocular Hypertension Treatment Study: a randomized trial determines that topical ocular hypotensive medication delays or prevents the onset of primary open-angle glaucoma. Arch Ophthalmol 2002;120:701-13; discussion 829-30.

11. Miglior S, Zeyen T, Pfeiffer N, Cunha-Vaz J, Torri V, Adamsons I. Results of the European Glaucoma Prevention Study. Ophthalmology 2005;112:366-75.

12. Gordon MO, Torri V, Miglior S, et al. Validated prediction model for the development of primary open-angle glaucoma in individuals with ocular hypertension. Ophthalmology 2007;114:10-9.

13. Zeyen T, Miglior S, Pfeiffer N, Cunha-Vaz J, Adamsons I. Reproducibility of evaluation of optic disc change for glaucoma with stereo optic disc photographs. Ophthalmology 2003;110:340-4.

14. Parrish RK, 2nd, Schiffman JC, Feuer WJ, et al. Test-retest reproducibility of optic disk deterioration detected from stereophotographs by masked graders. Am J Ophthalmol 2005;140:762-4.

15. Feuer WJ, Parrish RK, 2nd, Schiffman JC, et al. The Ocular Hypertension Treatment Study: reproducibility of cup/disk ratio measurements over time at an optic disc reading center. Am J Ophthalmol 2002;133:19-28.

16. Heijl A, Leske MC, Bengtsson B, Hyman L, Bengtsson B, Hussein M. Reduction of intraocular pressure and glaucoma progression: results from the Early Manifest Glaucoma Trial. Arch Ophthalmol 2002;120:1268-79.

17. Sommer A, Katz J, Quigley HA, et al. Clinical detectable nerve fiber atrophy precedes the onset of glaucomatous field loss. Arch Ophthalmol 1991;109:77-83.

18. Quigley HA, Katz J, Derick RJ, Gilbert D, Sommer A. An evaluation of optic disc and nerve fiber layer examinations in monitoring progression of early glaucoma damage. Ophthalmology 1992;99:19-28.

19. Zeyen TG, Caprioli J. Progression of disc and field damage in early glaucoma. Arch Ophthalmol 1993;111:62-5.

20. Johnson CA, Adams AJ, Casson EJ, Brandt JD. Progression of early glaucomatous visual field loss as detected by blue-onyellow and standard white-on-white automated perimetry. Arch Ophthalmol 1993;111:651-6.

21. Johnson CA, Adams AJ, Casson EJ, Brandt JD. Blue-on-yellow perimetry can predict the development of glaucomatous visual field loss. Arch Ophthalmol 1993;111:645-50.

22. Sample PA, Weinreb RN. Progressive color visual field loss in glaucoma. Invest Ophthalmol Vis Sci 1992;33:2068-71.

23. Sample PA, Boden C, Zhang Z, et al. Unsupervised machine learning with independent component analysis to identify areas of progression in glaucomatous visual fields. Invest Ophthalmol Vis Sci 2005;46:3684-92.
24. Tan JC, Hitchings RA. Optimizing and validating an approach for identifying glaucomatous change in optic nerve topography. Invest Ophthalmol Vis Sci 2004;45:1396-403.

25. Strouthidis NG, Scott A, Peter NM, Garway-Heath DF. Optic disk and visual field progression in ocular hypertensive subjects: detection rates, specificity, and agreement. Invest Ophthalmol Vis Sci 2006;47:2904-10.

26. Patterson AJ, Garway-Heath DF, Strouthidis NG, Crabb DP. A new statistical approach for quantifying change in series of retinal and optic nerve head topography images. Invest Ophthalmol Vis Sci 2005;46:1659-67.

27. Kamal DS, Garway-Heath DF, Hitchings RA, Fitzke FW. Use of sequential Heidelberg retina tomograph images to identify changes at the optic disc in ocular hypertensive patients at risk of developing glaucoma. Br J Ophthalmol 2000;84:993-8.

28. Johnson CA, Sample PA, Zangwill LM, et al. Structure and function evaluation (SAFE): II. Comparison of optic disk and visual field characteristics. Am J Ophthalmol 2003;135:148-54.

29. Hood DC, Kardon RH. A framework for comparing structural and functional measures of glaucomatous damage. Prog Retin Eye Res 2007;26:688-710.

30. Chauhan BC, McCormick TA, Nicolela MT, LeBlanc RP. Optic disc and visual field changes in a prospective longitudinal study of patients with glaucoma: comparison of scanning laser tomography with conventional perimetry and optic disc photography. Arch Ophthalmol 2001;119:1492-9.

31. Artes PH, Chauhan BC. Longitudinal changes in the visual field and optic disc in glaucoma. Prog Retin Eye Res 2005;24:333-54.

32. Wollstein G, Schuman JS, Price LL, et al. Optical coherence tomography longitudinal evaluation of retinal nerve fiber layer thickness in glaucoma. Arch Ophthalmol 2005;123:464-70.

33. Tan JC, Poinoosawmy D, Hitchings RA. Tomographic identification of neuroretinal rim loss in high-pressure, normalpressure, and suspected glaucoma. Invest Ophthalmol Vis Sci 2004;45:2279-85.

34. Tan JC, Hitchings RA. Reference plane definition and reproducibility in optic nerve head images. Invest Ophthalmol Vis Sci 2003;44:1132-7.

35. Tan JC, Hitchings RA. Approach for identifying glaucomatous optic nerve progression by scanning laser tomography. Invest Ophthalmol Vis Sci 2003;44:2621-6.

36. Kamal DS, Viswanathan AC, Garway-Heath DF, Hitchings RA, Poinoosawmy D, Bunce C. Detection of optic disc change with the Heidelberg retina tomograph before confirmed visual field change in ocular hypertensives converting to early glaucoma. $\mathrm{Br}$ J Ophthalmol 1999;83:290-4.

37. Girkin CA, Emdadi A, Sample PA, et al. Short-wavelength automated perimetry and standard perimetry in the detection of progressive optic disc cupping. Arch Ophthalmol 2000; 118:1231-6

38. Katz J, Congdon N, Friedman DS. Methodological variations in estimating apparent progressive visual field loss in clinical trials of glaucoma treatment. Arch Ophthalmol 1999;117:1137-42.

39. Wilson MR. Progression of visual field loss in untreated glaucoma patients and suspects in St Lucia, West Indies. Trans Am Ophthalmol Soc 2002;100:365-410. 
40. Lin SC, Singh K, Jampel HD, et al. Optic nerve head and retinal nerve fiber layer analysis: a report by the American Academy of Ophthalmology. Ophthalmology 2007;114:1937-49.

41. Sakata LM, DeLeon-Ortega J, Girkin CA. Selective perimetry in glaucoma diagnosis. Curr Opin Ophthalmol 2007;18:115-21.

42. Zangwill LM, Bowd C, Medeiros FA, Weinreb RN. Optic nerve imaging devices: recent advances. In: Grehn Sa, editor. Essentials in Ophthalmology: Glaucoma. Heidelberg: Springer-Verlag, 2004:63-91.

43. Sample PA, Medeiros FA, Racette L, et al. Identifying glaucomatous vision loss with visual function-specific perimetry in the diagnostic innovations in glaucoma study. Invest Ophthalmol Vis Sci 2006;47:3381-9.

44. Sharma P, Sample PA, Zangwill LM, Schuman JS. Diagnostic tools for glaucoma detection and management. Surv Ophthalmol 2008;in press.

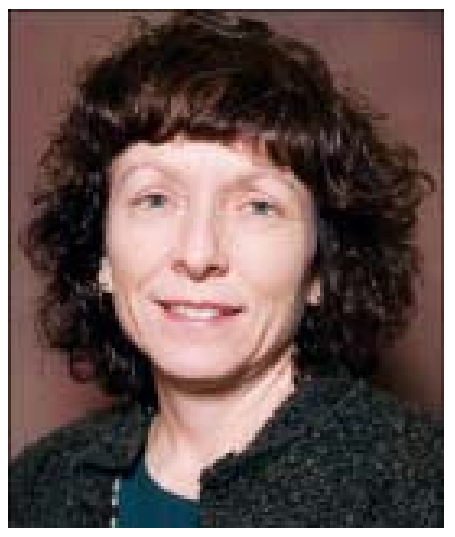

Dr Linda M Zangwill (zangwill@glaucoma.ucsd.edu) 